\title{
Sediment biogeochemistry and trace metal fluxes near the Thwaites and Pine Island Glaciers, Amundsen Sea
}

\author{
LISA C HERBERT ${ }^{1}$, ALLISON LEPP ${ }^{2}$, LAUREN SIMKINS ${ }^{2}$, \\ JULIA WELLNER ${ }^{3}$, SILKE SEVERMANN ${ }^{1}$ AND ROBERT \\ M. SHERRELL ${ }^{1}$ \\ ${ }^{1}$ Rutgers University \\ ${ }^{2}$ University of Virgina \\ ${ }^{3}$ University of Houston \\ Presenting Author: 1herbert@marine.rutgers.edu
}

The Amundsen Sea (AS) hosts the highest primary productivity per unit area observed on the Antarctic continental shelf, concentrated in coastal polynyas near the outlets of the fastest melting glaciers on Antarctica. These polynyas are highly dynamic carbon sinks where production is controlled by light and the availability of iron $(\mathrm{Fe})$. Previous studies indicate that the majority of the $\mathrm{Fe}$ in the polynya surface waters is delivered through upward transport of modified Circumpolar Deep Water that invades the deep shelf, acquires additional Fe, and enters the ice shelf cavities, where it is injected into the upper water column by the addition of meltwater buoyancy (the "meltwater pump"). While an Fe source from shelf sediments is suggested by observations and modeling to exceed a direct glacial meltwater source, the distribution and magnitude of the purported benthic Fe flux is unknown. To investigate the surface sediment biogeochemistry and the potential for a dominant benthic flux of $\mathrm{Fe}$ to the AS, sediment cores were collected at two sites close to the calving face of the Pine Island and Thwaites ice shelves in late summer 2020, and subsampled for pore water and solid sediment. Pore water was analyzed for Fe and other trace elements. Solid sediment was analyzed for porosity, along with grain size, organic carbon content, and total trace metal contents. Dissolved Fe fluxes were calculated from porewater gradients and porosity, revealing a spatially variable but potentially important input to the lower water column that could ultimately fertilize primary productivity in the polynyas via the meltwater pump. High flux and burial of labile organic carbon in the rapidly deposited sediments may increase benthic Fe reduction, creating a positive feedback loop between primary production and sediment $\mathrm{Fe}$ release. The dynamic behaviors of the proximal glaciers, ice shelves, and productive polynyas also appear to influence benthic biogeochemistry and trace metal behavior. These first-ever porewater metals data for the AS provide a basis for further investigation of $\mathrm{Fe}$ cycling and benthic-pelagic coupling in the AS, which will likely be impacted by accelerating glacial melt and changes in productivity patterns resulting from ongoing climate change. 